\title{
KNOWLEDGE, CONFIDENCE AND TRAINING IN CHILD PROTECTION ISSUES - A SURVERY OF TRAINEES VIEWS
}

\author{
P. Arora, H. Kanthimathinathan, V. Jones, P. Kapila \\ Paediatrics, North Middlesex Hospital, London, UK
}

Aim: To analyse the confidence, training and knowledge of child protection issues in doctors in training.

Methods: An anonymised online survey was sent to all paediatric trainees in the deanery.

Results: 218 trainees responded (27\%) working across all areas of paediatrics. $45.5 \%$ were ST1-3 and 51.9\% were ST4-8. Only 70\% had received child protection training within the last year and $3.7 \%$ had never received any training.

No-one rated themselves as 'very confident' in managing child protection issues. $66 \%$ of ST4- 8 and $22.4 \%$ of ST1-3. felt 'confident'. $11.2 \%$ of trainees felt 'not confident'. The most common reason was lack of experience (71\%) followed by 'stressful (38\%), 'litigation' (33\%) and 'lack of training' (32\%)

Ability to identify injuries that were not accidental was equal across training grades. Knowledge of Local Child protection procedures was excellent with nearly all trainees scoring $100 \%$.

Knowledge of Laming recommendations was heterogenous. The majority (87\%) felt that documentation should be completed within 24 hours of admission. More worryingly $70 \%$ felt that a child with CP concerns could be discharged without a GP. $25 \%$ felt that a nurse could discharge a child with CP concerns. $25 \%$ of trainees disagreed with the statement 'every instance of possible deliberate harm should be considered and treated as a potentially fatal disease'.

Conclusion: This has demonstrated trainees recognise physical abuse and are aware of local child protection procedures. However they still lack confidence in this area and are unaware of some of the Laming recommendations which could be addressed by formalised training. 